\title{
MOF modified pencil electrode for hydrogen peroxide detections
}

\author{
Mostafa H. Fytory ${ }^{1}$, Soha M. Hamdy ${ }^{1}$, A. A. Farghali ${ }^{2}$, Roland Ludwig ${ }^{3}$ and M.R. Saber ${ }^{*}$ \\ ${ }^{1}$ Chemistry department, Faculty of Sciences, Fayoum University, Fayoum, Egypt \\ ${ }^{2}$ Materials science and nanotechnology department, Faculty of postgraduate studies for advanced sciences, \\ Beni-suef university, Beni-suef, Egypt. \\ ${ }^{3}$ Department of Food Science and Technology BOKU - University of Natural Resources and Life Sciences, \\ Muthgasse 18, 1190 Vienna, Austria.
}

\begin{tabular}{l}
\hline A R T I C L E I N F O \\
\hline Keywords: \\
Pencil graphite electrode $(P G E), M O F$ \\
biosensors, $\mathrm{H}_{2} \mathrm{O}_{2}$ detection, CDH, Pt \\
electrode. \\
Abbreviations \\
MOF, Metal organic frame work \\
CDH, Cellobiose dehydrogenase \\
PGE, Pencil graphite electrode \\
LOD, Limit of detection
\end{tabular}

\section{INTRODUCTION:}

$\mathrm{H}_{2} \mathrm{O}_{2}$ is considered the most common reactive oxygen species (ROS) and byproduct of the oxidative metabolic pathway ( $\mathrm{Lu}, \mathrm{Wen}$, and $\mathrm{Li}$ 2006). Simple and reliable hydrogen peroxide $\left(\mathrm{H}_{2} \mathrm{O}_{2}\right)$ measurements are needed in different fields in recent years, because of the important role of $\mathrm{H}_{2} \mathrm{O}_{2}$ in chemicals production, fuel cells, biotechnology, environmental, pharmaceutical and clinical applications (Jia et al. 2014; Reza and Bagheri 2014; Sawangphruk et al. 2014;
Tang, Yuan, and Chai 2006; Toniolo et al. 2011).

Many approaches were introduced to detect $\mathrm{H}_{2} \mathrm{O}_{2}$ including chromatography (Toyo, Kashiwazaki, and Kato 2003), spectrometry (Matsubara, Kawamoto, and Takamura 1992), fluorescence, chemiluminescence (Taylor et al. 2006) and titrimetry (Hurdis and Romeyn 1954). Among all techniques, electrochemical methods in $\mathrm{H}_{2} \mathrm{O}_{2}$ detection are still the affordable choice due to their advantages (low cost, fast response and high

Corresponding Author: Dr. Mohamed R. Saber, Ph.D.

Lecturer of chemistry \& Materials sciences, Faculty of Sciences, Fayoum University

University Street, Fayoum 63511, Egypt.

Telephone: $\quad+202-01006036739$

Fax: $\quad+202-0846370025$

E-mail: msaber@fayoum.edu.eg 
sensitivity). Thus, many achievements in electrochemical detection of $\mathrm{H}_{2} \mathrm{O}_{2}$ have been reported (Chemishy 1989; Guascito et al. 2008; Lvovich and Scheeline 1997; MasuoAizawa, IsaoKarube 1974; Wu et al. 2006), of which the enzymatic and nonenzymatic hydrogen peroxide electrochemical sensing are the most common techniques in $\mathrm{H}_{2} \mathrm{O}_{2}$ detection (Zhenting Zhao, Qibiao Ou 2017).

Due to the high surface area and the porosity of MOF, many molecules could be loaded on it, which catalyze the target with a high catalytic activity that affords inherent sensitivity for the electrochemical detection. In the face of the enticing features of MOFs introduce them as an excellent material for electrode modification, still there are two challenges to be addressed: the design of redox active MOFs and the improvement on MOF conductivity(Pauliukaite et al. 2008). Moreover, because of their high surface areas, naked active sites, specific adsorption affinity and various pore sizes MOFs were used for electrode surface modification in order to detect trace amounts of compounds (Dong et al. 2016; Kung et al. 2015; Li et al. 2013; X. Wang et al. 2015; D. Zhang et al. 2015).

Due to the wide potential window, chemical inertness and low cost, carbonbased materials have been considered as an important electrode material for electrochemical biosensors. Different carbon allotropes have been used for biosensor fabrication for the detection of $\mathrm{H}_{2} \mathrm{O}_{2}$. Among the carbon-based electrodes, pencil graphite electrodes (PGE), glassy carbon electrodes (GCE) and carbon fiber electrodes (CFE) are three of the most widely used electrodes. Pencil graphite electrodes (PGEs) are carbon-based electrodes that are identified by their costeffectiveness, simplicity, commercial availability, high surface area, and high conductivity. PGEs are attractive materials for electrochemical sensing owing to their exclusive feature of "disposability" compared to other commonly used carbon- based electrodes (A.-N. Kawde, Baig, and Sajid 2016). In addition, PGEs are mechanically rigid and easy to modify and miniaturize (David, Badea, and Radu 2013). Modification of PGE with nanomaterials or direct formation of NPs on PGE surface enhances its surface area, which in turn results in high sensitivity and improved electrochemical activity towards the detection of target species (A.N. Kawde, Baig, and Sajid 2016). A variety of nanomaterials have been applied for modifications of PGE such as metal nanoparticles (Aziz and Kawde 2013a), conducting polymers, carbon-based materials (Kuralay, Dumangöz, and Tunç 2015). Due to high selectivity and sensitivity, portability, rapid analysis, and ease of availability, modified PGEs offer excellent opportunities for detections of many environmental and biological samples (Alipour, Reza, and Saadatirad 2013; Rezaei 2014; Tadi, Motghare, and Ganesh 2014). Moreover as reported very recently, modified PGEs show a high electrocatalytic activity toward $\mathrm{H}_{2} \mathrm{O}_{2}$ detection. (Aziz and Kawde 2013b; A. Kawde, Baig, and Temerk 2015; J. Zhang and Zheng 2015). Herein, sensors using pencil graphite were fabricated through a very simple process and modified with UiO-66 MOF. In addition, design, fabrication, and operation of a 2D scanning electrochemical micros-copy cell for the amperometric detection of enzymatically produced $\mathrm{H}_{2} \mathrm{O}_{2}$.

\section{MATERIALS AND METHODS: Materials and enzymes}

The MDA-MB-231 cell line, known as a wild-type for BRCA human triplenegative breast cancer cell line, was obtained from Vacsera (Dokki, Giza, Egypt) and processed in National Cancer Institute, Cairo University. The MDAMB-231 cells were cultured in DMEM medium (Sigma, St Louis, MO, USA) containing $10 \%$ fetal bovine serum along with $100 \mathrm{mg} / \mathrm{ml}$ streptomycin and 100 units/ml penicillin G (Sigma, St Louis, MO, USA). Cells were incubated in a 
humidified atmosphere with $5 \%$ (v/v) $\mathrm{CO}_{2}$ at $37^{\circ} \mathrm{C}$. For drug treatment, $10 \mathrm{mg}$ of olaparib (LKT Laboratories, USA) was dissolved in $1 \mathrm{ml}$ DMSO and stored at $-4^{\circ}$ $\mathrm{C}$ upon usage.

\section{CDH assay using cytochrome $c$ and DCIP}

$\mathrm{CDH}$ activity was measured based on monitoring the reduction of $20 \mu \mathrm{M}$ cytochrome c (cyt c) $(\varepsilon 550=19.6 \mathrm{mM}-1$ cm-1) or $0.3 \quad \mathrm{mM}$ 2,6dichlorophenolindophenol (DCIP) $(\varepsilon 520=$ $6.8 \mathrm{mM}-1 \mathrm{~cm}-1.100 \mu \mathrm{L}$ of the electron acceptor solution and $100 \mu \mathrm{L}$ lactose solution (30 $\mathrm{mM}$ in distilled water) was added to $780 \mu \mathrm{L} 100 \mathrm{mM}$ phosphate buffer, $\mathrm{pH}$ 6.0. Cuvettes were incubated in a water bath at $30^{\circ} \mathrm{C}$ for $20 \mathrm{~min}$. The reaction was monitored at 550 or $520 \mathrm{~nm}$ for $3 \mathrm{~min}$ at $30^{\circ} \mathrm{C}$ in a Lambda $35 \mathrm{UV}$ visible (UV-Vis) spectrophotom.

Fabrication of MOF modified Pencil Graphite Electrode (PGE).

All leads with a diameter of $0.5 \mathrm{~mm}$ were used as received. A copper wire was soldered to the pencil leads for electrical contact. Contacted leads of $\sim 1 \mathrm{~cm}$ length were put into standard borosilicate glass capillaries with filament (OD $1.50 \mathrm{~mm}$, ID $0.86 \mathrm{~mm}$, Sutter Instrument, Novato, CA, USA) leaving out $\sim 1 \mathrm{~mm}$ at one side of the capillary. At this side, the nozzle, including the salient part of the lead, was sealed using graphite conductive adhesive 154 (Electron Microscopy Sciences). The sealed leads were then polished using wet emery paper (P400 and P2500) until they were in the plane with the surrounding glass capillary. The electrode was then rinsed with distilled water and dried at room temperature overnight. PGE microelectrode were modified with simple way. A solution of $1.5 \mathrm{mg} \mathrm{ml}^{-1} \mathrm{UIO}-66(\mathrm{Zr})$ $\mathrm{MOF}$ in $\mathrm{HQ}-\mathrm{H}_{2} \mathrm{O}$ was prepared by sonicating for $15 \mathrm{~min}$. The prepared electrodes were immersed in a $3 \mathrm{~mL}$ tube containing $1 \mathrm{ml}$ of the synthesized UIO-66 ( $\mathrm{Zr}) \mathrm{MOF}$ and sonicated for $30 \mathrm{~min}$ at room temperature. The UIO-66( $\mathrm{Zr})$ modified electrodes were then washed gently with distilled water and dried at room temperature before use.

\section{Electrochemical Measurements.}

All electrochemical measurements were performed with a standard three-electrode setup employing an $\mathrm{Ag} / \mathrm{AgCl}$-reference electrode $(3 \mathrm{M} \mathrm{KCl})$, a platinum wire as a counter electrode and a pencil electrode as a working electrode using a PGSTAT204 Potentiostat/Galvanostat (Metrohm Autolab, Utrecht, The Netherlands). Calibration curves were obtained by using chronoamperometry applying a potential of $-0.4 \mathrm{~V}$ vs $\mathrm{Ag} / \mathrm{AgCl}(3 \mathrm{M} \mathrm{KCl})$ adding aliquots of $\mathrm{H}_{2} \mathrm{O}_{2}$ to $50 \mathrm{~mL}$ stirred KPP buffer solution, $\mathrm{pH}$ 6.0, at defined time intervals and plotting the current I versus the respective $\mathrm{H}_{2} \mathrm{O}_{2}$ concentrations.

\section{RESULTS:}

Characterization of UiO-66 and modification of carbon electrodes.

The Zr-based MOF UiO-66 was synthesized as mentioned above in materials and methods section. The resulting white powder was collected and the crystal structure of the prepared UIO66 MOF was examined using Powder Xray diffraction (PXRD). XRD pattern, FTIR spectra and FE SEM of the synthesized UIO-66 MOF is shown in (Figure 1a, b and 2).

\section{Fabrication of MOF modified Pencil} Graphite Electrodes (PGEs)

Briefly, (PGEs) as a sensor were simply designed by connecting graphite pencil ( $0.5 \mathrm{~mm}$ diameter, $2 \mathrm{~mm}$ length) with copper wire as an electrical conductor in glass capillary. A PGE was immersed in the synthesized UIO-66 MOF solution for $15 \mathrm{~min}$ at room temperature. After washing and drying, chronoamperometry was applied in $50 \mathrm{mM}$ of KPP pH 6.0 for both bare PGE and modified electrode.

\section{Amperometric response of working} electrode.

The amperometric responses of the bare and MOF modified Pencil Graphite Electrodes (PGEs) microelectrodes in 
comparison with platinum microelectrode were measured by successive injections of different concentrations of $\mathrm{H}_{2} \mathrm{O}_{2}$ in $50 \mathrm{mM}$ KPP (pH 6.0) under stirring at an applied potential of $-0.4 \mathrm{~V}$ with a time interval of $60 \mathrm{~s}$ as indicated in Fig 3. (Figure 3a) shows the stable amperometric response of Pt microelectrode with a $25 \mu \mathrm{M}$ diameter. The steady-state current was obtained after a very reasonable time (2 second) of additions of $\mathrm{H}_{2} \mathrm{O}_{2}$. (Figure 3b) shows the amperometric responses of the bare PGE (solid red line) UIO-66 modified PGE (solid black line) at $-0.4 \mathrm{~V}$ upon successive additions of $\mathrm{H}_{2} \mathrm{O}_{2}$ with interval time $30 \mathrm{~s}$. The UIO-66 modified PGE (Fig. 3b black) offered a very well-defined and sensitive signal for each addition of $\mathrm{H}_{2} \mathrm{O}_{2}$, in comparison with the bare PGE (Figure.

3b red) that showed a weak signal.

Calibration curve of working electrodes, determination of LOD and sensitivity.

A calibration curve observed at the different types of microelectrode was undertaken to assess the potential impact of MOF modifications on microelectrode. Figure 4 shows the calibration data for the different types of microelectrodes over the range of $0.25-5.0 \mathrm{mM} \mathrm{H} \mathrm{H}_{2} \mathrm{O}_{2}$. For a $\mathrm{Pt}$ microelectrode $(25 \mu \mathrm{m}$ in diameter $)$ the active surface area of $\mathrm{Pt}$, assuming a diskshaped surface, was calculated according to $\mathrm{A}=\pi \mathrm{r}^{2}=0.000490874 \mathrm{~mm}^{2}$. The quality of the calibration data obtained for the $\mathrm{Pt}$ microelectrode is remarkable. A linear response is observed for the $\mathrm{Pt}$ microelectrode. Weighted regression of the data $\left(\mathrm{R}^{2}=0.996\right)$ over the range of 0.25 $5.0 \mathrm{mM}$ yields a sensitivity of the $\mathrm{Pt}$ microelectrode calculated from the slope of the calibration plot between 0.25 and 5 $\mathrm{mM}$ of $4.16 \mu \mathrm{A} \mathrm{mM}{ }^{-1} \mathrm{~mm}^{-2}$. The limit of detection (LOD), considered as the limiting current for $\mathrm{H}_{2} \mathrm{O}_{2}$ detection and measured as 3 times the standard deviation of the blank divided by sensitivity was found to be $200.45 \mu \mathrm{M}$. The Limit of quantification (LOQ), was calculated as 10 times the standard deviation of the blank divided by sensitivity was found to be
$668.12 \mu \mathrm{M}$. The surface area of a graphite pencil electrode $(0.5 \mathrm{~mm}$ in diameter $)$, assuming a disk-shaped surface, was calculated according to $A=\left(\pi r^{2}\right)=0.1964$ $\mathrm{mm}^{2}$. Figure $4 \mathrm{~b}$ shows the electrocatalytic activity of bare PGE and the UIO-66/GPE for amperometric detection of $\mathrm{H}_{2} \mathrm{O}_{2}$ at an operating potential of $-0.4 \mathrm{~V}$ upon successive additions of $0.25,0.5,0.75,1$, 2, 3, 4, and $5 \mathrm{mM} \mathrm{H}_{2} \mathrm{O}_{2}$. Weighted regression of the data for the UIO-66/GPE and the bare PGE $\left(\mathrm{R}^{2}=0.996\right.$ and 0.995, respectively) over the range of $0.25-5 \mathrm{mM}$ yielded in a sensitivity of $2.16 \mu \mathrm{A} \mathrm{mM}^{-1}$ $\mathrm{mm}^{-2}$ and $0.751 \mu \mathrm{A} \mathrm{mM}^{-1} \mathrm{~mm}^{-2}$, respectively. The LODs were 610 and $0.214 \mu \mathrm{M}$, respectively. The LOQs were 2070 and $803 \mu \mathrm{M}$, respectively. A comparison of the limit of detection, the linear range and the sensitivity of the here prepared microelectrodes with MOFs modified $\mathrm{H}_{2} \mathrm{O}_{2}$ sensors from the literature are given in (Table 1).

\section{D-scanning electrochemical microscopy for measuring $\mathrm{H}_{2} \mathrm{O}_{2}$ as a by- product of enzymatic reactions.}

The SECM set-up used in the electrochemical enzymatic reaction measurements was described previously in published work(Sun 2012). The main components of a SECM set-up are the micromanipulator used for positioning of the SECM tip in $\mathrm{x}-, \mathrm{y}-$, and $\mathrm{z}$ - direction, a potentiostat, a computer and an ultramicroelectrode. Here, we used MOF modified carbon electrodes as SECM tips in the homemade electrochemical cell. All SECM measurements were performed in $50 \mathrm{mM}$ KPP, pH 6.0. A buffered solution has been chosen to be suitable with the enzyme conditions used in the measurements. Experiments were carried out applying a standard three-electrode setup comprising a $\mathrm{Ag} / \mathrm{AgCl}(3 \mathrm{M} \mathrm{KCl})$ silverchloride electrode was used as a reference electrode, a Pt wire as a counter electrode and MOF modified and unmodified pencil as working electrode. A cellulose filter paper was used as the basis 
for protein immobilization. Fig 5 schematically illustrates the enzymatic reaction occurring in the electrochemical cell. It shows that $\mathrm{CDH}$ catalyzes the oxidation of cellobiose to cellobionic acid followed by the reduction of $\mathrm{H}_{2} \mathrm{O}_{2}$ to $\mathrm{O}_{2}$.

MOF/Pencil electrode as amperometric sensor for the detection of $\mathrm{H}_{2} \mathrm{O}_{2}$ produced from $\mathrm{CDH}$ immobilized on cellulose.

The collected amperometric response is proportional to the concentration of the present $\mathrm{H}_{2} \mathrm{O}_{2}$. With the help of the respective calibration curves, the actual concentration of $\mathrm{H}_{2} \mathrm{O}_{2}$ was calculated. For the SECM experiments we defined and keept constant a specific scan rate for the forward and backward scans $\left(\mu \mathrm{m} \mathrm{s}^{-1}\right)$. Thus, we were able to convert the raw data from the chronoamperometric experiments (current and time) to concentrations of $\mathrm{H}_{2} \mathrm{O}_{2}$ and distance. Plotting of these variables reveals a spatial resolution of $\mathrm{H}_{2} \mathrm{O}_{2}$ concentrations in the bulk solution and is shown in (Figure 6) for the tested electrode.

\section{DISCUSSION:}

The structure of the synthesized sample is confirmed by the good agreement between the XRD patterns of the sample and the simulated pattern. FTIR spectra of the MOF sample were collected in the range of $400-400 \mathrm{~cm}^{-1}$ as $\mathrm{KBr}$ pellets (Figure 1b). The stretching vibration and bending vibration bands around 1607 and $1408 \mathrm{~cm}^{-1}$ are attributed to $v_{\text {as }}(\mathrm{COO})$ and $v_{\mathrm{s}}(\mathrm{COO})$ which confirms the presence of terephthalate ligands. The band centered at $3391 \mathrm{~cm}^{-1}$ in the frequency region between $\left(3800-3100 \mathrm{~cm}^{-}\right.$ ${ }^{1}$ ) can be assigned to the hydrogen-bonded adsorbed water and $v(\mathrm{C}-\mathrm{H})$ stretching modes of DMF molecules. The aromatic and aliphatic $v(\mathrm{C}-\mathrm{H})$ modes of the benzene ring and $\mathrm{DMF}$ are indicated by the presence of the weak bands in the 3100$2850 \mathrm{~cm}^{-1}$ region. The low frequency region is dominated by an intense band centered at $1658 \mathrm{~cm}^{-1}$ and two narrow bands at 1255 and $1102 \mathrm{~cm}^{-1}$. These bands could be assigned to the $\delta\left(\mathrm{OH}_{2}\right), \delta\left(\mathrm{CH}_{3}\right)$ and $\delta(\mathrm{C}-\mathrm{O})$ vibration of the physisorbed water and DMF molecules, respectively. The morphological structure of the pristine sample was examined using FE-SEM at different magnification scales $(2 \mu \mathrm{m}$ and $5 \mu \mathrm{m})$. As shown in Fig 2. 1c, 2c, and 3c, the prepared UiO-66 appears as relatively uniform particles with a particle size in the nanoscale range (100-200 $\mathrm{nm})$.

Fig 3 a shows the stable amperometric response of $\mathrm{Pt}$ microelectrode with a 25 $\mu \mathrm{M}$ diameter. The steady-state current was obtained after a very reasonable time (2 second) of additions of $\mathrm{H}_{2} \mathrm{O}_{2}$. Fig $3 b$ shows the amperometric responses of the bare PGE (solid red line) UIO-66 modified PGE (solid black line) at $-0.4 \mathrm{~V}$ upon successive additions of $\mathrm{H}_{2} \mathrm{O}_{2}$ with interval time $30 \mathrm{~s}$. The UIO-66 modified PGE (Fig. $3 \mathrm{~b}$ black) offered a very well-defined and sensitive signal for each addition of $\mathrm{H}_{2} \mathrm{O}_{2}$, in comparison with the bare PGE (Fig. 3b red) that showed a weak signal. This is a direct effect of the MOF surface modifications on the electrocatalytic properties of the prepared electrode. The data from Fig $3 b$ for both bare PGE and UIO-66/PGE confirmed that the bare PGE displayed poor electrocatalytic properties with respect to the reductions of $\mathrm{H}_{2} \mathrm{O}_{2}$ compared to that observed for the UIO66/PGE. The reduction of $\mathrm{H}_{2} \mathrm{O}_{2}$ at the UIO-66/PGE could be attributed to the excellent electrocatalytic properties of the UIO-66 MOF. Moreover, the UIO-66 MOF played as suitable mediators to shuttle electrons between $\mathrm{H}_{2} \mathrm{O}_{2}$ and PGE, and they facilitated the electrochemical generation following electron exchange with $\mathrm{H}_{2} \mathrm{O}_{2}$.

The accuracy of the data is very reasonable, which make $\mathrm{Pt}$ microelectrode sensor able to quantitatively measure $\mathrm{H}_{2} \mathrm{O}_{2}$ amperometrically. This fact gives a suggestion for the potential use of $\mathrm{Pt}$ microelectrode in a wide range of applications from very low levels of 
hydrogen peroxide produced in vivo due to oxidative cell stress to the millimolar levels presented in some industrial processes (Amatore et al. 2000). Moreover, the range of linearity offered covers more than that obtained by field strips common in commercial use (Evans et al. 2002).

With UIO-66 modification, the sensitivity of a pencil graphite electrode could thus be improved by almost a factor of four. The high sensitivity of modified electrode comes from the fact that MOF on the surface of PGE increases the surface area of the electrode, therefore, increases the electrocatalytic performance of the electrode towards $\mathrm{H}_{2} \mathrm{O}_{2}$ reduction. The above discussion indicates that UIO-66 PGE offers higher electrocatalytic properties towards the detection of $\mathrm{H}_{2} \mathrm{O}_{2}$ in comparison with the bare PGE. A comparison of the limit of detection, the linear range and the sensitivity of the here prepared microelectrodes with MOFs modified $\mathrm{H}_{2} \mathrm{O}_{2}$ sensors from the literature are given in Table 1. Based on this comparative study, it was found that the UIO-66/carbon electrodes can offer affordable LOD and high sensitivity for the detection of $\mathrm{H}_{2} \mathrm{O}_{2}$

Recently, new approaches were applied based on PGE for sensing of $\mathrm{H}_{2} \mathrm{O}_{2}$ (A.-N. Kawde, Baig, and Sajid 2016).Modification of PGE with nanomaterials has aroused great attention in $\mathrm{H}_{2} \mathrm{O}_{2}$ detection owing to its high sensitivity. For measuring $\mathrm{H}_{2} \mathrm{O}_{2}$ produced from cellobiose dehydrogenase we used a UIO-66 MOF modified PGE. A very fine drop of CDH enzyme was immobilized on the middle of a cellulose paper with a length of $2.5 \mathrm{~cm}$ fixed on the bottom of the homemade electrochemical cell. The cell was filled with $50 \mathrm{mM} \mathrm{KPP}, \mathrm{pH} 6.0$, serving both as buffer solution and electrolyte, and $10 \mathrm{mM}$ cellobiose solution serving as a substrate for CDH. UIO66/PGE was used as SECM tip. The measurement started by moving UIO-
66/PGE above the immobilized enzyme in the electrochemical cell using the micromanipulator. The electrode was then scanned successively forwards and backwards along the y-axes over the whole length of the cell, thereby screening over the immobilized $\mathrm{H}_{2} \mathrm{O}_{2}$ producing $(\mathrm{CDH})$ and $\mathrm{H}_{2} \mathrm{O}_{2}$ consuming (CDH/LPMO) enzymes. The $\mathrm{CDH}$ catalyzed generated $\mathrm{H}_{2} \mathrm{O}_{2}$ travels vertically out from the immobilized $\mathrm{CDH}$ in a hemispherical shape and is amperometrically detected with the positioned UIO-66/PGE tip at a very close distance to the immobilized $\mathrm{CDH}$.

Figure 6. represents the data collected from the amperometric detection of $\mathrm{H}_{2} \mathrm{O}_{2}$ at the applied potential of $-0.4 \mathrm{~V}$ using a MOF modified PGE as working electrode. The solid line represents the data collected from the $1^{\text {st }}$ forward scan and the dotted line refers to the $2^{\text {nd }}$ forward scan. The data show that in the beginning of $1^{\text {st }}$ forward scan (far away from the immobilized enzyme) almost no change in current was observed. In close vicinity of the immobilized $\mathrm{CDH}$ the current starts to increase reaching a peak maximum, when the electrode tip is positioned above the enzyme. Continuing the scan and thus moving the electrode further away from the immobilized $\mathrm{CDH}$, the current decreases and soon reaches its initial background level. The higher background current in the $2^{\text {nd }}$ forward scan may be attributable to further diffusion of the generated $\mathrm{H}_{2} \mathrm{O}_{2}$ into the bulk solution over the whole cell distance. The lower peak maximum in the $2^{\text {nd }}$ forward scan simply results from a shorter, in terms of time, stop in scanning in order to reach a maximum current right above the enzyme (as was done in the $1^{\text {st }}$ forward scan). From the data in Figure 6 and the explanations mentioned above, we can conclude that a UIO-66 MOF modified PGE is a suitable detector for $\mathrm{H}_{2} \mathrm{O}_{2}$ produced from cellobiose fueled $\mathrm{CDH}$. 


\section{CONCLUSION:}

The fabrication of a MOF modified pencil graphite microelectrode with high sensitivity to detect the enzymatic production and conversion of $\mathrm{H}_{2} \mathrm{O}_{2}$ by cellulose bound enzymes and to determine the concentration and diffusion of $\mathrm{H}_{2} \mathrm{O}_{2}$ were achieved. $\mathrm{CDH}$ produces $\mathrm{H}_{2} \mathrm{O}_{2}$ in the presence of cellobiose as a substrate. Comparisons between $\mathrm{Pt}$ microelectrode and both of bare and modified pencil graphite electrode used for $\mathrm{H}_{2} \mathrm{O}_{2}$ detections were done.

\section{ACKNOWLEDGEMENT:}

This work was funded European Union joint master program (TEMPUS). The authors would like to thank his supervision committee for their assistance, expert guidance, sustained interest, fruitful revising of this manuscript.

\section{REFERENCES:}

Alipour, Esmaeel, Mir Reza, and Afsaneh Saadatirad. 2013. "Electrochimica Acta Simultaneous Determination of Dopamine and Uric Acid in Biological Samples on the Pretreated Pencil Graphite Electrode." Electrochimica Acta 91: $36-42$.

http://dx.doi.org/10.1016/j.electacta. 2012.12.079.

Amatore, C et al. 2000. "Analysis of Individual Biochemical Events Based on Artificial Synapses Using Ultramicroelectrodes: Cellular Oxidative Burst." Faraday Discussions 116: 319-33.

Arul, P., and S. Abraham John. 2017. "Silver Nanoparticles Built-in Zinc Metal Organic Framework Modified Electrode for the Selective NonEnzymatic Determination of H2O2." Electrochimica Acta 235: 680-89.

http://dx.doi.org/10.1016/j.electacta. 2017.03.097.
Aziz, Abdul, and Abdel-nasser Kawde. 2013a. "Gold NanoparticleModified Graphite Pencil Electrode for the High-Sensitivity Detection of Hydrazine." Talanta 115: 21421.

http://dx.doi.org/10.1016/j.talanta.2 013.04.038.

2013b. "Nanomolar Amperometric Sensing of Hydrogen Peroxide Using a Graphite Pencil Electrode Modified with Palladium Nanoparticles." Microchim Acta 843: 837-43.

Chemishy, Analytical. 1989. “An Electrochemical Sensor for Hydrogen Peroxide Based on Peroxidase Adsorbed on a Spectrographic Graphite Electrode." Electroanalysis 1: 465-68.

David, Iulia Gabriela, Irinel Adriana Badea, and Gabriel Lucian Radu. 2013. "Disposable Carbon Electrodes as an Alternative for the Direct Voltammetric Determination of Alkyl Phenols from Water Samples.” Turk J Chem 37: 91-100.

Dong, Sheying et al. 2016. "A Simple Strategy to Fabricate High Sensitive 2,4-Dichlorophenol Electrochemical Sensor Based on Metal Organic Framework Cu3(BTC)2." Sensors and Actuators, B: Chemical 222: 972-79.

http://dx.doi.org/10.1016/j.snb.2015 .09.035.

Evans, Struart a G et al. 2002. "Detection of Hydrogen Peroxide at Mesoporous Platinum Microelctrodes." Analytical Chemistry 74(6): 1322-26.

Guascito, M. R. et al. 2008. "A New Amperometric Nanostructured Sensor for the Analytical Determination of Hydrogen Peroxide." Biosensors and 
Bioelectronics 24(4): 1057-63.

Hurdis, Everett C, and Hendrik Romeyn. 1954. "Accuracy of Determination of Hydrogen Peroxide by Cerate Oxidimetry." Analytical Chemistry 26: $320-25$.

Jia, Ningming et al. 2014. "A Simple NonEnzymatic Hydrogen Peroxide Sensor Using Gold NanoparticlesGraphene-Chitosan Modified Electrode." Sensors and Actuators, B: Chemical 195: 165-70. http://dx.doi.org/10.1016/j.snb.2014 .01 .043 .

Kawde, Abdel-Nasser, Nadeem Baig, and Muhammad Sajid. 2016. "Graphite Pencil Electrodes as Electrochemical Sensors for Environmental Analysis: A Review of Features, Developments, and Applications." RSC Adv. 6(94): 91325-40.

http://xlink.rsc.org/?DOI=C6RA174 66C.

Kawde, Abdel-nasser, Nadeem Baig, and Yassin Temerk. 2015. "A Facile Fabrication of Platinum Nanoparticle-Modified Graphite Pencil Electrode for Highly Sensitive Detection of Hydrogen Peroxide." JOURNAL OF ELECTROANALYTICAL CHEMISTRY 740: 68-74. http://dx.doi.org/10.1016/j.jelechem .2015.01.005.

Kung, Chung Wei et al. 2015. "PorphyrinBased Metal-Organic Framework Thin Films for Electrochemical Nitrite Detection." Electrochemistry Communications 58: 51-56. http://dx.doi.org/10.1016/j.elecom.2 015.06.003.

Kuralay, Filiz, Mehmet Dumangöz, and Selma Tunç. 2015. "Carbon Nanotubes Coated Graphite Surfaces for Highly Sensitive
Nitrite Detection." Talanta 144: 1133-38.

http://dx.doi.org/10.1016/j.talanta.2 015.07.095.

Li, Yingwei et al. 2013. "Electrochemical Behavior of Metal-Organic Framework MIL-101 Modified Carbon Paste Electrode: An Excellent Candidate for Electroanalysis." Journal of Electroanalytical Chemistry 709: 65-69.

http://dx.doi.org/10.1016/j.jelechem .2013.09.017.

Lu, Xianbo, Zhenhai Wen, and Jinghong Li. 2006. "Hydroxyl-Containing Antimony Oxide Bromide Nanorods Combined with Chitosan for Biosensors." Biomaterials 27(33): 5740-47.

Lvovich, Vadim, and Alexander Scheeline. 1997. "Amperometric Sensors for Simultaneous Superoxide and Hydrogen Peroxide Detection." Anal.Chem. 69(3): 3579-87.

MasuoAizawa, IsaoKarube, ShuichiSuzuki. 1974. "A Specific Bio-Electrochemical Sensor for Hydrogen Peroxide." Analytica Chimica Acta 69: 431-37.

Matsubara, Chiyo, Naoki Kawamoto, and Kiyoko Takamura. 1992. "An UltraHigh Sensitivity Spectrophotometric Reagent for Hydrogen Peroxide." 117(November): 1781-84.

Pauliukaite, Rasa, Samo B. Hočevar, Emily A. Hutton, and Božidar Ogorevc. $2008 . \quad$ "Novel Electrochemical Microsensor for Hydrogen Peroxide Based on IronRuthenium Hexacyanoferrate Modified Carbon Fiber Electrode." Electroanalysis 20(1): 47-53.

Reza, Mohammad, and Akbar Bagheri. 
2014. "Sensors and Actuators B: Chemical Nonenzymatic Glucose and Hydrogen Peroxide Sensors Based on Catalytic Properties of Palladium Nanoparticles / Poly ( 3 , 4-Ethylenedioxythiophene Nanofibers." Sensors \& Actuators: B. Chemical 195: 85-91. http://dx.doi.org/10.1016/j.snb.2014 .01 .015 .

Rezaei, Heydari-bafrooei B. 2014. "Development of a Voltammetric Procedure Based on DNA Interaction for Sensitive Monitoring of Chrysoidine, a Banned Dye, in Foods and Textile Effluents." Sensors \& Actuators: B. Chemical 202: 224-31. http://dx.doi.org/10.1016/j.snb.2014 .05 .001 .

Sawangphruk, Montree et al. 2014. "Silver Nanodendrite Modified Graphene Rotating Disk Electrode for Nonenzymatic Hydrogen Peroxide Detection." Carbon 70(0): 287-94. http://dx.doi.org/10.1016/j.carbon.2 014.01 .010

Sherino, Bibi, Sharifah Mohamad, Siti Nadiah Abdul Halim, and Ninie Suhana Abdul Manan. 2018. "Electrochemical Detection of Hydrogen Peroxide on a New Microporous Ni-metal Organic Framework Material-Carbon Paste Electrode." Sensors and Actuators, B: Chemical 254: 1148-56. http://dx.doi.org/10.1016/j.snb.2017 .08 .002 .

Sun, Yu. 2012. "Scanning Electrochemical Microscopy Studies of Nickel Surfaces and T24 Single Live Cells.”

Tadi, Kiran Kumar, R V Motghare, and V Ganesh. 2014. "Electrochemical Detection of Sulfanilamide Using Pencil Graphite Electrode Based on
Molecular Imprinting Technology." Electroanalysis 26: 2328 - 2336.

Tang, Dianping, Ruo Yuan, and Yaqin Chai. 2006. "Electron-Transfer Mediator Microbiosensor Fabrication Based on Immobilizing HRP-Labeled Au Colloids on Gold Electrode Surface by 11Mercaptoundecanoic Acid Monolayer." Electroanalysis 18(3): 259-66.

Taylor, Publisher, M Aizawa, Y Ikariyama, and H Kuno. 2006. "Photovoltaic Determination of Hydrogen Peroxide with A Biophotodiode." Analytical Letters 17(July 2015): 555-64.

Toniolo, Rosanna et al. 2011. "Simultaneous Detection of Ascorbic Acid and Hydrogen Peroxide by Flow-Injection Analysis with a Thin Layer DualElectrode Detector." Electroanalysis 23(3): 628-36.

Toyo, Toshimasa, Tomoaki Kashiwazaki, and Masaru Kato. 2003. "On-Line Screening Methods for Antioxidants Sca v Enging Superoxide Anion Radical and Hydrogen Peroxide by Liquid Chromatography with Indirect Chemiluminescence Detection." 60: 467-75.

Wang, Li et al. 2016. "Cu-Hemin MetalOrganic-Frameworks/Chitosan-

Reduced Graphene Oxide Nanocomposites with PeroxidaseLike Bioactivity for Electrochemical Sensing." Electrochimica Acta 213: 691-97. http://dx.doi.org/10.1016/j.electacta. 2016.07.162.

Wang, Xue, Xianbo Lu, Lidong $\mathrm{Wu}$, and Jiping Chen. 2015. "3D MetalOrganic Framework as Highly Efficient Biosensing Platform for Ultrasensitive and Rapid Detection 
of Bisphenol A." Biosensors and Bioelectronics 65: 295-301. http://dx.doi.org/10.1016/j.bios.201 4.10.010.

Wu, Shuo et al. 2006. "Electrodeposition of Silver - DNA Hybrid Nanoparticles for Electrochemical Sensing of Hydrogen Peroxide and Glucose." Electrochemistry Communications 8: 1197-1203.

$\mathrm{Xu}$, Zhaodong, Lizi Yang, and Cailing Xu. 2015."Pt@UiO-66 Heterostructures for Highly Selective Detection of Hydrogen Peroxide with an Extended Linear Range.” Analytical Chemistry 87(6): 3438-44.

Yang, Lizi, Cailing Xu, Weichun Ye, and Weisheng Liu. 2015. "An Electrochemical Sensor for $\mathrm{H} 2 \mathrm{O} 2$ Based on a New Co-Metal-Organic Framework Modified Electrode." Sensors and Actuators, B: Chemical 215: 489-96. http://dx.doi.org/10.1016/j.snb.2015 .03.104.

Zhang, Daojun et al. 2015. "3D Porous Metal-Organic Framework as an Ef
Fi Cient Electrocatalyst for Nonenzymatic Sensing Application." Talanta 144: 117681.

http://dx.doi.org/10.1016/j.talanta.2 015.07.091.

Zhang, Jian, and Jianbin Zheng. 2015. "Analytical Methods An EnzymeFree Hydrogen Peroxide Sensor Based." Analytical Methods 7: 1788-93. http://dx.doi.org/10.1039/C4AY028 $81 \mathrm{C}$.

Zhenting Zhao, Qibiao Ou, Xiuwen Yin and Jianqi Liu. 2017. "Nanomaterial-Based

Electrochemical Hydrogen Peroxide Biosensor." International Journal of Biosensors \& Bioelectronics 2(3): 25-28.

Zhou, Echeng, Yanwu Zhang, Yijun Li, and Xiwen He. 2014. " $\mathrm{Cu}(\mathrm{II})$-Based MOF Immobilized on Multiwalled Carbon Nanotubes: Synthesis and Application for Nonenzymatic Detection of Hydrogen Peroxide with High Sensitivity." Electroanalysis 26(11): 2526-33. 

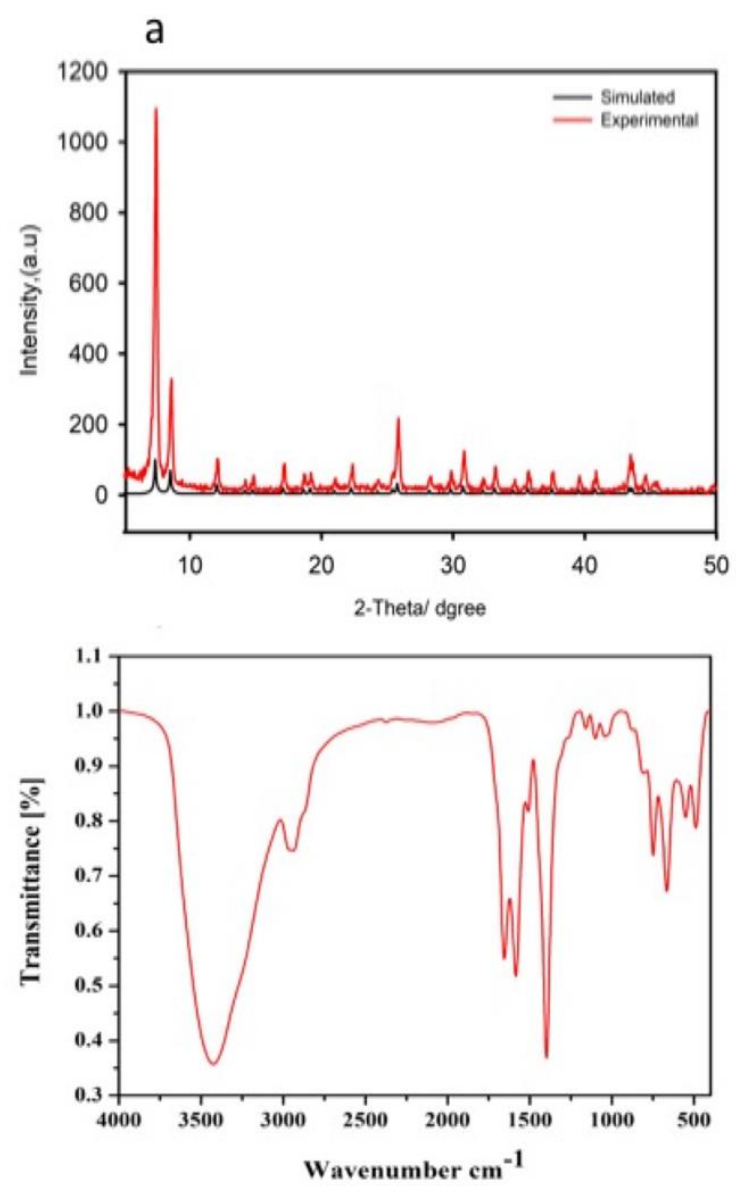

Figure (1): XRD patterns of prepared UIO-66 MOF and simulated UIO-66 MOF (a), FTIR spectra (b).
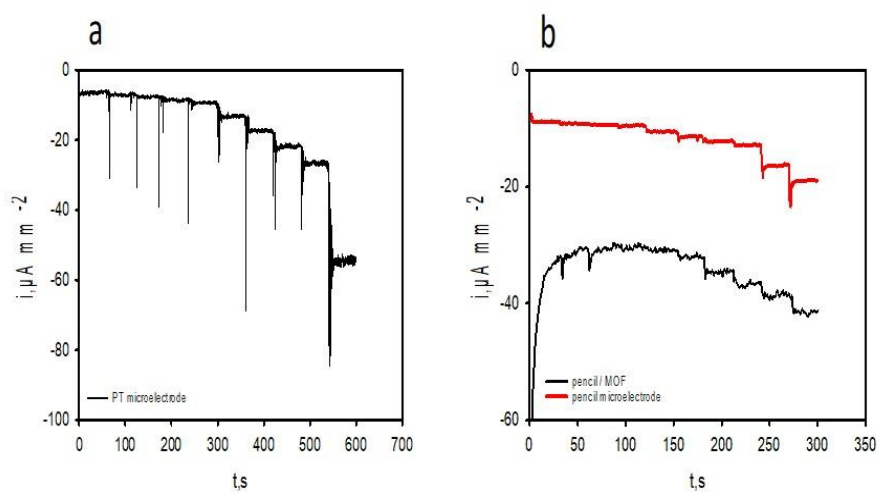

Figure (3): The amperometric response of indicated microelectrodes upon successive injection of $\mathrm{H}_{2} \mathrm{O}_{2}$ in $50 \mathrm{mM}$ $\mathrm{KPP}, \mathrm{pH} 6.0$, at $-0.4 \mathrm{~V}$. (a) platinum microelectrode with a diameter of $25 \mu \mathrm{m}$, (b) pencil electrode with a diameter of $0.5 \mathrm{~mm}$ unmodified and modified with MOF.

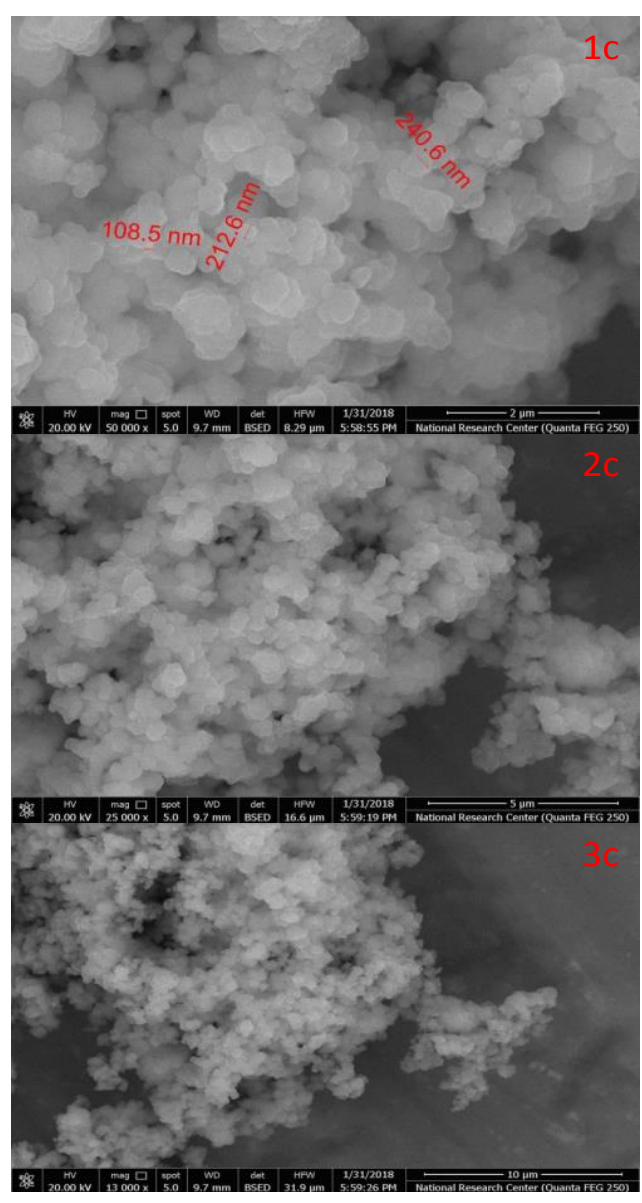

Figure (2): FE SEM of prepared UIO-66 MOF at different magenifications scale (1c $2 \mu \mathrm{m}, 2 \mathrm{c} 5 \mu \mathrm{m}, 3 \mathrm{c} 10 \mu \mathrm{m})$.
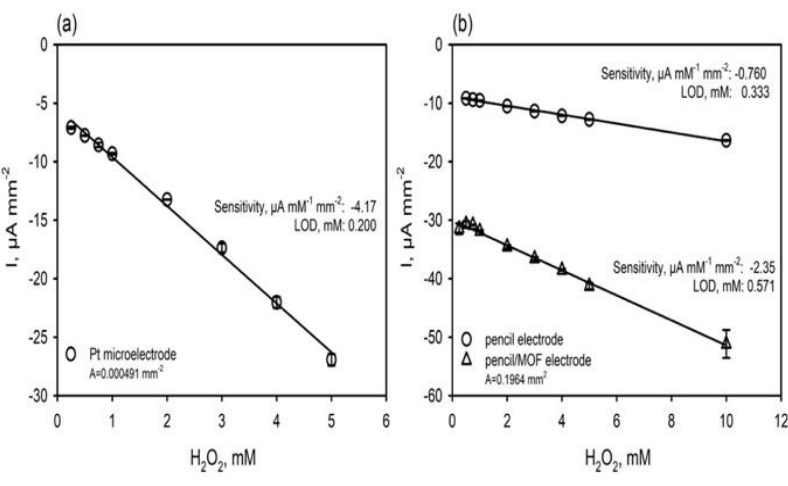

Figure (4): Calibration curves of indicated microelectrodes for hydrogen peroxide detection. (a) platinum microelectrode with a diameter of 25 $\mu \mathrm{m}$, (b) pencil electrode with a diameter of $0.5 \mathrm{~mm}$ unmodified and modified with MOF. 


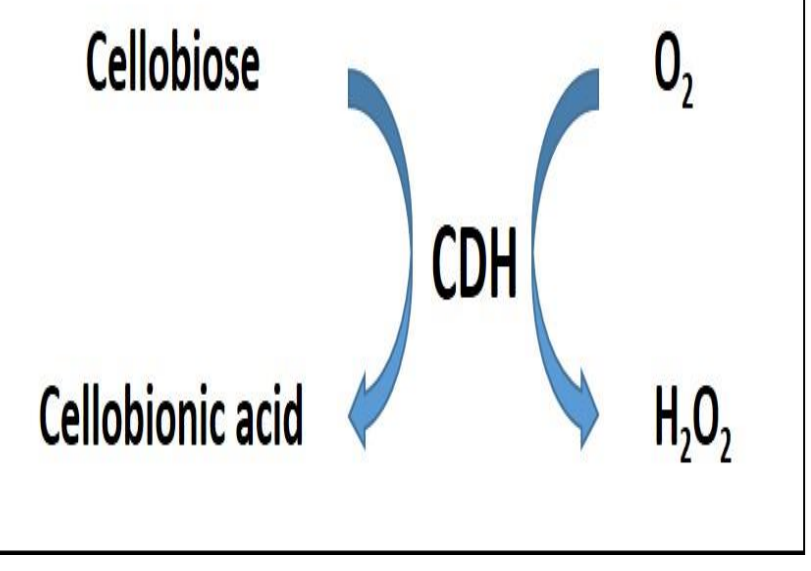

Figure (5): Schematic representation of reactions taking place between pencil electrode and $\mathrm{CDH}$ immobilized on surface of cellulose paper in the electrochemical cell.

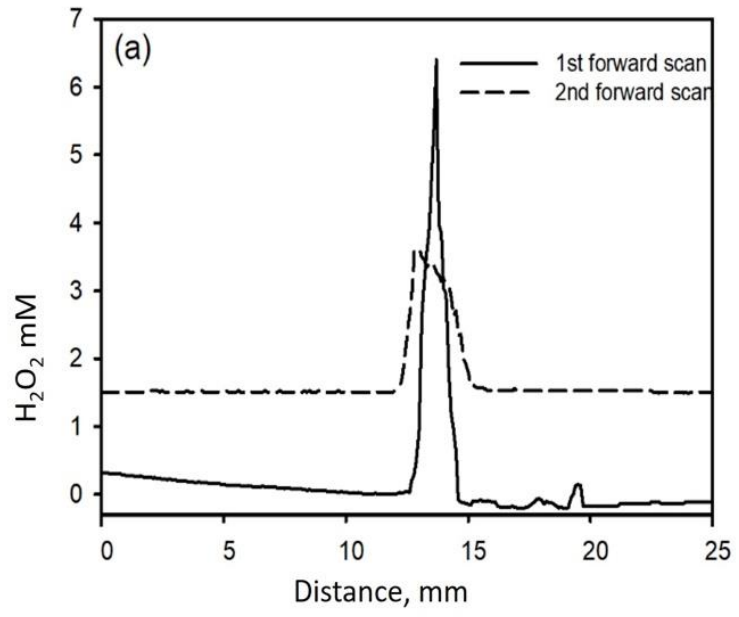

Figure (6): 2D-scanning electrochemical microscopy for detection $\mathrm{H}_{2} \mathrm{O}_{2}$ produced by $\mathrm{CDH}$ using (a) modified pencil electrode/CDH. 
Table 1 Comparison of the analytical parameters values of MOF modified electrode for hydrogen peroxide detections

\begin{tabular}{|c|c|c|c|c|}
\hline Modified electrode & $\begin{array}{l}\text { Linear } \\
\text { range } \\
(\mathbf{m M})\end{array}$ & $\begin{array}{l}\text { Limit of } \\
\text { detection } \\
\text { (LOD), } \\
{[\mu \mathrm{M}]}\end{array}$ & Sensitivity & $\operatorname{Ref}^{a}$ \\
\hline UIO-66/PGE $^{2}$ & $0.5-20$ & 610 & $2.16 \mu \mathrm{AmM}^{-1} \mathrm{~mm}^{-2}$ & This work \\
\hline AP-Ni-MOF/CPE 3 & $0.004-60$ & 0.9 & NP & $\begin{array}{l}\text { (Sherino et al. } \\
\text { 2018) }\end{array}$ \\
\hline AgNPs-Zn- MOF/GCE ${ }^{4}$ & $0.001-5$ & 0.067 & NP & $\begin{array}{l}\text { (Arul and John } \\
\text { 2017) }\end{array}$ \\
\hline Cu-hemin MOFs/CS-rGO & $\begin{array}{l}0.00006- \\
0.41\end{array}$ & 0.019 & $14.5 \mu \mathrm{AM}^{-1}$ & $\begin{array}{l}\text { (L. Wang et al. } \\
\text { 2016) }\end{array}$ \\
\hline $\mathrm{Pt} @ \mathrm{UiO}-66 / \mathrm{GCE}$ & $0.005-14.75$ & 3.06 & $75.33 \mu \mathrm{A} \mathrm{mM}^{-1} \mathrm{~cm}^{-2}$ & $\begin{array}{l}\text { (Xu, Yang, and } \mathrm{Xu} \\
2015)\end{array}$ \\
\hline Cu-MOF-MWCNT/ GCE & $0.03-0.07$ & 0.46 & NP & (Zhou et al. 2014) \\
\hline Cu-MOF/CPE & $0.001-0.9$ & 1.0 & $\mathrm{NP}$ & $\begin{array}{l}\text { (D. Zhang et al. } \\
2015 \text { ) }\end{array}$ \\
\hline Co-MOF/GCE & $0.005-9.0$ & 3.76 & $83.10 \mathrm{~A} \mathrm{mM}^{-1} \mathrm{~cm}^{-2}$ & (Yang et al. 2015) \\
\hline
\end{tabular}

